\title{
Awareness of Lung Cancer Symptoms and Risk Factors in General Population
}

\author{
Hanna Maria Hanson', Mait Raag², Merje Adrat'1, Tanel Laisaar ${ }^{3,4}$ \\ ${ }^{1}$ Rocca al Mare School, Tallinn, Estonia \\ ${ }^{2}$ Department of Public Health, University of Tartu, Tartu, Estonia \\ ${ }^{3}$ Department of Thoracic Surgery, Tartu University Hospital, Tartu, Estonia \\ ${ }^{4}$ Lung Clinic, Tartu University, Tartu, Estonia \\ Email: tanel.laisaar@kliinikum.ee
}

How to cite this paper: Hanson, H.M., Raag, M., Adrat, M. and Laisaar, T. (2017) Awareness of Lung Cancer Symptoms and Risk Factors in General Population. Open Journal of Respiratory Diseases, 7, 1-11. https://doi.org/10.4236/ojrd.2017.71001

Received: September 14, 2016

Accepted: December 13, 2016

Published: December 16, 2016

Copyright (C) 2017 by authors and Scientific Research Publishing Inc. This work is licensed under the Creative Commons Attribution International License (CC BY 4.0).

http://creativecommons.org/licenses/by/4.0/

cc) (†) Open Access

\begin{abstract}
Introduction: Lung cancer is often diagnosed in a late stage, which might be related to lack of risk factors and symptoms awareness. Aim of this study was to evaluate these factors. Methods: A survey was conducted to assess the awareness of lung cancer risk factors and symptoms. Kruskal-Wallis, Fisher and chi-square tests were used to compare the groups. Results: Altogether 403 participants (108 male; median age 29 (range 13 to 74) years; 98 smokers, 90 ex-smokers and 212 non-smokers) completed the survey (321 filled in online questionnaire, 82 were interviewed face-to-face). Three per cent of the respondents were unable to name any lung cancer risk factor, $36 \%$ named one and $61 \%$ named two or more. Smoking was mentioned most commonly, others far less often. When presented with a list of lung cancer risk factors, 99.7\% of respondents recognised two or more; most commonly smoking (99\%) and second-hand smoking (95\%). Concerning symptoms, $17 \%$ were unable to name any, $21 \%$ named one and $62 \%$ named two or more. Prolonged cough was mentioned most often (59\%), followed by dyspnea (45\%) and chest pain (30\%). When presented with a list, $99 \%$ of respondents recognised two or more symptoms; most often prolonged cough (86\%), weakness (85\%) and chest pain (82\%). There were no statistical differences in lung cancer symptom, risk factor or prognosis awareness among smokers, ex-smokers and nonsmokers. There were some differences related to age, sex, education and type of used questionnaire. Conclusions: Awareness of lung cancer risks and symptoms is moderate in general population without major differences between smokers and non-smokers.
\end{abstract}

\section{Keywords}

Smoking, Lung Cancer, Risk Factors, Symptoms, Public Awareness 


\section{Introduction}

Commission of the European Communities has identified cancer (including lung cancer) as one of the most frequent causes of death in Europe and called for European Union wide cooperation. The Commission Communication on Action against Cancer: European Partnership sets the goal to reduce cancer prevalence by $15 \%$ by 2020 [1]. Estonia also has a National Cancer Strategy for 2007-2015, which states as one of the goals to reduce the occurrence of preventable malignant cancer cases. According to the document, this can be achieved by promoting healthy lifestyle and rising risk factor awareness [2]. Research supports this claim, showing that more than half of the cancer cases could be avoided with modern knowledge [3]. Lung cancer is one of the most common types of cancers worldwide [4] and also in Estonia, accounting for roughly $10 \%$ of all cancer cases [5].

Majority of lung cancer cases are diagnosed in a late stage, which might be at least partly related to the lack of lung cancer risk factors, symptoms and prognosis awareness.

Lung cancer is considered treatable only in early stages therefore early detection is also very important. Better symptom awareness is believed to aid early stage discovery [6].

Current study was conducted to evaluate lung cancer risk factors and symptoms awareness in general population.

\section{Materials and Methods}

To assess the lung cancer awareness of the general population a questionnaire was created by a senior investigator (TL). No previously validated questionnaire was available. Full questionnaire is provided as an attachment (see Appendix).

Study data were collected from December 2012 until April 2013. Majority of the participants were surveyed online, the link to the electronic questionnaire was posted on social media and on various discussion boards. The rest of the participants were interviewed face to face. For this purpose participants were recruited in various public spaces-stores, streets etc. All interviews were conducted by first author of the manuscript (HMH) and carried out strictly according to the questionnaire. Exactly the same questionnaire was used online.

\subsection{Awareness of Risk Factors}

The questionnaire included 3 questions with the aim of gauging risk factor awareness. First the participants were asked to recall lung cancer risk factors. Then they had to choose ones related to lung cancer from a given list of 8 most common risk factors. All the risk factors listed were connected to lung cancer. The third question asked the participant to assess the importance of smoking as a lung cancer risk factor.

\subsection{Awareness of Symptoms}

Two questions helped to identify awareness of lung cancer symptoms. First one 
asked the participants to recall symptoms related to lung cancer, second one provided a list of 10 most common symptoms and participants had to choose ones related to lung cancer. All symptoms listed were related to lung cancer.

\subsection{Additional Questions}

The questionnaire also included general questions about lung cancer. Participants were asked whether lung cancer occurs more often in men or women and whether it is treatable. Participants were also asked to provide their gender, age, education level and smoking habits.

\subsection{Statistics}

Kruskal-Wallis and Fisher's exact tests were used to find out factors associated with awareness.

No formal approval from ethical committee was obtained as no interventions were performed and no identifying data were collected from the study participants.

\section{Results}

A total of 403 people participated, 82 people were surveyed face to face on the street by one investigator and 321 study subjects filled in the questionnaire online. Participants' characteristics are listed in Table 1.

Table 1. Demographic characteristics of study participants.

\begin{tabular}{|c|c|c|c|c|c|c|}
\hline & \multicolumn{2}{|c|}{ Overall } & \multicolumn{2}{|c|}{ Interview } & \multicolumn{2}{|c|}{$\begin{array}{c}\text { Electronic } \\
\text { questionnaire }\end{array}$} \\
\hline & $\mathrm{N}$ & $\%$ & $\mathrm{~N}$ & $\%$ & $\mathrm{~N}$ & $\%$ \\
\hline \multicolumn{7}{|l|}{ Age, in years } \\
\hline$<20$ & 76 & 18.9 & 12 & 14.6 & 64 & 19.9 \\
\hline $20-29$ & 130 & 32.3 & 32 & 39.0 & 98 & 30.5 \\
\hline $30-39$ & 75 & 18.6 & 18 & 22.0 & 57 & 17.8 \\
\hline $40-49$ & 78 & 19.4 & 12 & 14.6 & 66 & 20.6 \\
\hline$>49$ & 44 & 10.9 & 8 & 9.8 & 36 & 11.2 \\
\hline \multicolumn{7}{|l|}{ Education level } \\
\hline Primary & 42 & 10.4 & 5 & 6.1 & 37 & 11.5 \\
\hline Secondary & 118 & 29.3 & 32 & 39.0 & 86 & 26.8 \\
\hline Tertiary & 182 & 45.2 & 2 & 2.4 & 50 & 15.6 \\
\hline Vocational & 52 & 12.9 & 43 & 52.4 & 139 & 43.3 \\
\hline Other & 9 & 2.2 & 0 & 0 & 9 & 2.8 \\
\hline \multicolumn{7}{|l|}{ Gender } \\
\hline Male & 108 & 26.8 & 37 & 45.1 & 71 & 22.1 \\
\hline Female & 295 & 73.2 & 45 & 54.9 & 250 & 77.9 \\
\hline \multicolumn{7}{|l|}{ Smoking Status } \\
\hline Smoker & 98 & 24.5 & 10 & 24.4 & 88 & 22.0 \\
\hline Non-smoker & 212 & 53.0 & 52 & 63.4 & 160 & 50.3 \\
\hline Former smoker & 90 & 22.5 & 20 & 12.2 & 70 & 27.7 \\
\hline
\end{tabular}




\subsection{Awareness of Risk Factors}

Out of the all participants $11(2.7 \%, 95 \%$ CI $1.4 \%-4.8 \%)$ were unable to recall any risk factors, $125(31.0 \%, 95 \%$ CI 26.5\% - 35.8\%) recalled one, and 267 $(66.3 \%, 95 \%$ CI $61.4 \%-70.9 \%)$ recalled two or more with a median of 2 risk factors named. The risk factor recalled most often was smoking (95.6\%, 95\% CI $93.3 \%-97.5 \%)$ followed by previous lung cancer or family history of lung cancer (31.3\%, 95\% CI 26.8\% - 36.0\%) and air pollution (24.6\%, 95\% CI 20.4\% - 29.1\%) (Table 2).

Number of risk factors recalled was not connected to the education level ( $\mathrm{p}=$ $0.753)$, gender $(p=0.198)$ age $(p=0.753)$ or smoking habits $(p=0.670)$ of the study subjects.

When selecting risk factors from a provided list only one participant chose one factor, the rest of the participants $(99.8 \%$, 95\% CI 98.6\% - 100.0\%) picked two or more with a median of 6 risk factors. Most commonly selected risk factor was smoking (99.0\%, 95\% CI 97.5\% - 99.7\%) followed by second-hand smoking (95.0\%, 95\% CI 92.4\% - 96.9\%) and previous lung cancer or family history of lung cancer $(86.6 \%, 95 \%$ CI $82.9 \%-89.8 \%)$.

In this question age was connected to the outcome $(\mathrm{p}=0.043)$. Older people recognised more risk factors. Gender $(p=0.417)$; education level $(p=0.092)$ and smoking habits did not affect the results $(\mathrm{p}=0.958)$.

When asked about the role of smoking in developing lung cancer 342 respondents $(84.9 \%, 95 \%$ CI $81.0 \%-88.2 \%)$ thought it had a significant effect. Forty-four people $(10.9 \%, 95 \%$ CI $8.0 \%-4.4 \%)$ thought that it has an effect, but

Table 2. Lung cancer risk factors recalled and recognised by study participants.

\begin{tabular}{|c|c|c|c|c|}
\hline \multirow[t]{2}{*}{ Risk factor } & \multicolumn{2}{|c|}{ Recalled } & \multicolumn{2}{|c|}{ Recognised } \\
\hline & $\mathrm{N}$ & $\begin{array}{c}\% \\
95 \% \text { CI }\end{array}$ & $\mathrm{N}$ & $\begin{array}{c}\% \\
95 \% \text { CI }\end{array}$ \\
\hline Smoking & 386 & $\begin{array}{c}95.8 \\
93.3-97.5\end{array}$ & 399 & $\begin{array}{c}99 \\
97.5-99.7\end{array}$ \\
\hline Second-hand smoking & 68 & $\begin{array}{c}16.9 \\
13.3-20.9\end{array}$ & 383 & $\begin{array}{c}95 \\
92.4-96.9\end{array}$ \\
\hline Air pollution & 99 & $\begin{array}{c}24.6 \\
20.4-29.1\end{array}$ & 321 & $\begin{array}{c}79.7 \\
75.4-83.5\end{array}$ \\
\hline Other lung diseases & 15 & $\begin{array}{c}3.7 \\
2.1-6.1\end{array}$ & 242 & $\begin{array}{c}60.0 \\
55.1-64.5\end{array}$ \\
\hline $\begin{array}{l}\text { Previous lung cancer or } \\
\text { family history of lung } \\
\text { cancer }\end{array}$ & 126 & $\begin{array}{c}31.3 \\
26.8-36.0\end{array}$ & 349 & $\begin{array}{c}86.6 \\
82.9-89.8\end{array}$ \\
\hline Chemicals & 27 & $\begin{array}{c}6.7 \\
4.5-9.6\end{array}$ & 293 & $\begin{array}{c}72.7 \\
68.1-77.0\end{array}$ \\
\hline Asbestos & 24 & $\begin{array}{c}6.0 \\
3.9-8.7\end{array}$ & 280 & $\begin{array}{c}69.5 \\
64.7-73.9\end{array}$ \\
\hline Radiation & 18 & $\begin{array}{c}4.5 \\
2.7-7.0\end{array}$ & 259 & $\begin{array}{c}64.3 \\
59.4-69.0\end{array}$ \\
\hline
\end{tabular}


not a significant one. Ten $(2.5 \%, 95 \%$ CI $1.2 \%$ - 4.5\%) people said maybe and 7 $(1.7 \%, 95 \%$ CI $0.7 \%-3.5 \%)$ people thought that other risk factors had a bigger effect. No respondents thought that there was no link between smoking and lung cancer.

Statistically not significant, but clear trend was seen that none-smokers considered smoking to be more important risk factor than ex-smokers and current smokers $(p=0.057)$. Older patients believed more commonly that other causes than smoking are more important LC risk factors $(\mathrm{p}=0.021)$. Education level $(\mathrm{p}=$ $0.843)$ and gender $(\mathrm{p}=0.307)$ did not affect the results.

\subsection{Awareness of Symptoms}

Out of all the respondents 67 (16.6\%, 95\% CI 13.1\% - 20.6\%) were unable to recall any symptoms, $85(21.1 \%, 95 \%$ CI $17.2 \%$ - 25.4\%) named one and 251 (62.3\%, 95\% CI 57.3\% - 67.0\%) named two or more with a median of 2 symptoms named. Most commonly recalled symptom was prolonged cough $(59.1 \%$, 95\% CI $54.1 \%-63.9 \%)$, followed by dyspnoea (45.4\%, 95\% CI 40.5\% - 50.4\%) and chest pain $(29.8 \%, 25.4 \%-34.5 \%)$ (Table 3$)$.

Number of symptoms recalled was influenced by gender $(\mathrm{p}=0.001)$. Female named more symptoms compared to male. Answers were not related to the level of education ( $\mathrm{p}=0.315)$, age $(\mathrm{p}=0.894)$ or smoking habits $(\mathrm{p}=0.636)$.

Table 3. Lung cancer symptoms recalled and recognised by study participants.

\begin{tabular}{|c|c|c|c|c|}
\hline \multirow[t]{2}{*}{ Symptom } & \multicolumn{2}{|c|}{ Recalled } & \multicolumn{2}{|c|}{ Recognised } \\
\hline & $\mathrm{N}$ & $\begin{array}{c}\% \\
95 \% \mathrm{CI}\end{array}$ & $\mathrm{N}$ & $\begin{array}{c}\% \\
95 \% \mathrm{CI}\end{array}$ \\
\hline Prolonged cough & 238 & $\begin{array}{c}59.1 \\
54.1-63.9\end{array}$ & 345 & $\begin{array}{c}85.6 \\
81.8-88.9\end{array}$ \\
\hline Fatigue & 79 & $\begin{array}{c}19.6 \\
15.8-23.8\end{array}$ & 344 & $\begin{array}{c}85.4 \\
81.5-88.7\end{array}$ \\
\hline Chest pain & 120 & $\begin{array}{c}29.8 \\
25.4-34.5\end{array}$ & 331 & $\begin{array}{c}82.1 \\
78.0-85.8\end{array}$ \\
\hline Haemoptysis & 70 & $\begin{array}{c}17.4 \\
13.8-21.4\end{array}$ & 319 & $\begin{array}{c}79.2 \\
74.9-83.0\end{array}$ \\
\hline Dyspnoea & 183 & $\begin{array}{c}45.4 \\
40.5-50.4\end{array}$ & 314 & $\begin{array}{c}77.9 \\
73.5-81.9\end{array}$ \\
\hline Weight loss & 27 & $\begin{array}{c}6.7 \\
4.5-9.6\end{array}$ & 311 & $\begin{array}{c}77.2 \\
72.8-81.2\end{array}$ \\
\hline Loss of appetite & 7 & $\begin{array}{c}1.7 \\
0.7-3.5\end{array}$ & 254 & $\begin{array}{c}63.0 \\
58.1-67.8\end{array}$ \\
\hline Wheeze & 5 & $\begin{array}{c}1.2 \\
0.4-2.9\end{array}$ & 223 & $\begin{array}{c}55.3 \\
50.3-60.3\end{array}$ \\
\hline $\begin{array}{c}\text { Prolonged respiratory } \\
\text { infection }\end{array}$ & 14 & $\begin{array}{c}3.5 \\
1.9-5.8\end{array}$ & 214 & $\begin{array}{c}53.1 \\
48.1-58.1\end{array}$ \\
\hline Hoarseness & 8 & $\begin{array}{c}2.0 \\
0.9-3.9\end{array}$ & 201 & $\begin{array}{c}49.8 \\
44.9-54.9\end{array}$ \\
\hline
\end{tabular}


When selecting symptoms from a list 4 people $(1.0 \%, 95 \%$ CI $0.3 \%-2.5 \%)$ were able to identify only one liked with lung cancer, 399 (99.0\%, 95\% CI 97.4\% $99.7 \%$ ) chose two or more with a median of 7 symptoms. Most commonly recognised symptoms were prolonged cough $(85.6 \%$, 95\% CI 81.8 - 88.9), fatigue (85.4\%, 95\% CI 81.5 - 88.7) and chest pain (82.1\%, 95\% CI 78.0 - 85.8).

Number of symptoms recognised was not affected by the level of education ( $\mathrm{p}=$ $0.108)$, age $(p=0.264)$, gender $(p=0.150)$ or smoking habits $(p=0.696)$ of the respondent.

\subsection{Other Questions}

No respondents thought that lung cancer only occurs in males, 254 people $(63.0 \%, 95 \%$ CI $58.1 \%$ - 67.8\%) thought it occurs more often in males than females [which is true in Estonia (5)], 140 people (34.7\%, 95\% CI 30.1\% - 39.6\%) thought it affects both genders equally and 9 people $(2.2 \%$, 95\% CI $1.0 \%-4.2 \%)$ thought it affects females more often.

There were no noticeable connections between answers and education ( $\mathrm{p}=$ $0.645)$, age $(\mathrm{p}=0.057)$, gender $(\mathrm{p}=0.507)$ or smoking habits $(\mathrm{p}=0.355)$.

Sixteen respondents $(4.0 \%, 95 \%$ CI $2.3 \%-6.4 \%)$ thought that lung cancer can never be cured, 354 (87.8\%, 95\% CI 84.2\% - 90.9\%) believed it was only possible in early stages, $32(7.9 \%, 95 \%$ CI $5.5 \%-11.0 \%)$ thought it is nearly always possible in the modern age and $1(0.3 \%, 0.0 \%-1.4 \%)$ thought it was always curable. There was no connection between answers and education $(\mathrm{p}=0.191)$, age $(\mathrm{p}=$ $0.143)$, gender $(\mathrm{p}=0.127)$ or smoking habits $(\mathrm{p}=0.184)$.

\subsection{Style of Questionnaire}

The answers to some questions were affected by the way the questions were asked (face-to-face or online). Specifically questions 2 ( $\mathrm{p}<0.001), 4(\mathrm{p}<0.001)$, $5(\mathrm{p}<0.001)$ and $7(\mathrm{p}<0.001)$ were affected.

In question 2 (recognising risk factors) people interviewed on the street were able to recognise more factors with $67.1 \%$ (95\% CI $55.8 \%-77.1 \%$ ) of people recognising 7 or 8 risk factors while $44.5 \%$ (95\% CI $39.0 \%-50.2 \%$ ) people participating online recognised 7 or 8 factors.

In question 4, no people interviewed on the street were able to name 5 or more symptoms (14 people interviewed online were able to do so). Also more people on the street were unable to name any symptoms (34.1\% (95\% CI $24.0 \%$ $45.4 \%$ ) compared to $12.5 \%$ (95\% CI 9.1\% - 16.6\%) online).

In question 5 people on the street recognised more symptoms with $51.2 \%$ (95\% CI $39.9 \%-62.4 \%$ ) picking 9 or 10 , while $29.9 \%$ (95\% CI $24.9 \%-35.2 \%$ ) of people on the internet were able to do that.

In question 7 more people interviewed on the street believed that in the modern age lung cancer is almost always curable (18.3\% (95\% CI 10.6 - 28.4) versus $5.3 \%$ (95\% CI 3.1\% - 8.3\%) online).

Out of people interviewed online 5.0\% (95\% CI 2.9\% - 8.0\%) believed that lung cancer is incurable while none of the ones interviewed on the street agreed 
with this. Still most people in both groups believed that lung cancer is curable in early stages $(89.4 \%$ (95\% CI $85.5 \%$ - 92.6\%) online and $81.7 \%$ (95\% CI $71.6 \%$ $89.4 \%$ ) on the street).

There were some differences in terms of demographical characteristics of the two groups. While age distribution was similar in both groups $(p=0.903)$, there were differences in gender $(p<0.0001)$, education level $(p=0.0006)$ and smoking status $(\mathrm{p}=0.013)$.

\section{Discussion}

Awareness of LC risks and symptoms is moderate in Estonian population. Similar or somewhat lower cancer risks and symptoms awareness findings have been published in previous studies analysing lung cancer in UK [7] or Canada [8], breast cancer [9] or cervical cancer [10].

Most important LC risk factor is smoking and that is also the most well known risk factor by study subjects, which may be due to the amount of campaigns focused on that topic. Other risk factors were poorly recognised. Surprisingly more people named family history or previous lung cancer history and air pollution more often as risk factor than second-hand smoking. However, when provided a list of risk factors, $95 \%$ of our study subjects recognised second-hand smoking as a LC risk factor compared to $67 \%$ from a previous French study [11]. There are probably differences in risk factor awareness between different countries. Comparing our results with a previous study performed in UK [7], Estonians were able to name more symptoms, namely air pollution and family history or previous lung cancer. Variations between different countries might be explained by extent of anti-tobacco warnings and campaigns performed in respective countries [12].

Knowledge about LC symptoms was also relatively low, but as lung cancer does not have very specific symptoms, the finding was quite predictable. However, the most often named symptoms-cough, chest pain and dyspnoea are the most common LC symptoms, which unfortunately in majority of cases indicate advanced stage cancer [13]. Again, when comparing to study performed in UK [7], Estonians named more and also somewhat different symptoms. Shortness of breath, haemoptysis and chest pain were most commonly named in UK, other symptoms were named by less than $10 \%$ of respondents [7]. In our study, six symptoms were named by more than $10 \%$ of respondents, including cough, chest pain, dyspnoea, fatigue, hoarseness and haemoptysis.

The participants were significantly better at recognising risk factors and symptoms from a given list. However this is not a good indication of awareness as respondents can simply guess. Very similar finding was demonstrated in previous lung, breast and cervical cancer studies [7] [8] [9] [10].

Smoking as a major lung cancer risk factor was expected to influence considerably people's beliefs and knowledge about LC. Out of all the participants in our study $24.8 \%$ were current smokers, which corresponds well to the $26 \%$ smoking rate in Estonia as stated by Eurobarometer [14]. However, the smoking status 
influenced only study subjects' beliefs about role of smoking as a lung cancer risk factor. Not statistically significant, but a clear trend was seen that nonesmokers considered smoking to be more important risk factor than ex-smokers and current smokers $(\mathrm{p}=0.057)$. Some previous studies conducted in other countries have shown connections between smoking status and awareness [9]. Walker et al. analysed lung cancer risk factor awareness among persons with one or several risk factors [8]. They demonstrated that current smokers, compared to previous or non-smokers, consider smoking and exposure to second-hand smoke or air pollution less important lung cancer risk factors [8].

Older people in our study thought less frequently that smoking is a risk factor of LC $(\mathrm{p}=0.021)$. Fact that smoking causes several diseases including lung cancer is evident more than 50 years, however this knowledge is widely distributed only during last few decades. Therefore older people might still consider smoking as not so important risk factor of lung cancer.

In the future it is advisable to carry out more campaigns rising awareness of both symptoms and risk factors. More studies with bigger samples could help to identify possible focus groups for these campaigns.

One limitation of our study is that the study population was relatively young, with female predominance and more highly educated than population average. While answers to some questions were affected by age, gender or education level of the respondent, the data showed no significant overall impact of these factors.

The style of questionnaire used (online or face-to-face interview) affected the results of some questions.

In one previous study, similarly telephone and internet survey was used [8]. Authors did not provide data of results obtained either by phone or online survey and did not analyse the results separately. Another limitation of our study was that no power calculation was made before the study to compare online and face-to-face interview results.

Awareness of lung cancer risks and symptoms is moderate in general population without major differences between smokers and non-smokers, although smoking specifically is considered to be more important risk factor by non-smokers than smokers. After providing a list of answers, considerably more of lung cancer risk factors and symptoms are recognised by respondents.

Questioning environment somewhat influenced the answers and it should be taken into consideration when planning future studies.

\section{References}

[1] (2009) Communication from the Commission to the European Parliament, the Council, the European Economic and Social Committee and the Committee of the Regions on Action against Cancer: European Partnership. http://www.ec.europa.eu/health/archive/ph information/dissemination/diseases/do cs/com 2009 291.en.pdf

[2] Ministry of Social Affairs (2007) National Cancer Strategy 2007-2015. https://www.sm.ee/sites/default/files/content-editors/national cancer_strategy 200 7 2015eng.pdf 
[3] Colditz, G.A., Wolin, K.Y. and Gehlert, S. (2012) Applying What We Know to Accelerate Cancer Prevention. Science Translational Medicine, 4, 127rv4. https://doi.org/10.1126/scitranslmed.3003218

[4] Ferlay, J., Soerjomataram,I., Dikshit, R., Eser, S., Mathers, C., Rebelo, M., Parkin, D.M., Forman, D. and Bray, F. (2015) Cancer Incidence and Mortality Worldwide: Sources, Methods and Major Patterns in GLOBOCAN 2012. International Journal of Cancer, 136, E359-E386. https://doi.org/10.1002/ijc.29210

[5] National Institute for Health Development (2016) Health Statistics and Health Research Database.

http://pxweb.tai.ee/esf/pxweb2008/Database en/Morbidity/04Malignant\%20neopla sms/04Malignant\%20neoplasms.asp

[6] Robb, K., Stubbings, S., Ramirez, A., Macleod, U., Austoker, J., Waller, J., Hiom, S. and Wardle, J. (2009) Public Awareness of Cancer in Britain: A Population-Based Survey of Adults. British Journal of Cancer, 101, S18-S23. https://doi.org/10.1038/sj.bjc.6605386

[7] Simon, A.E., Juszczyk, D., Smyth, N., Power, E., Hiom, S., Peake, M.D. and Wardle, J. (2012) Knowledge of Lung Cancer Symptoms and Risk Factors in the UK: Development of a Measure and Results from a Population-Based Survey. Thorax, 67, 426432. https://doi.org/10.1136/thoraxinl-2011-200898

[8] Walker, S.L., Saltman, D.L., Colucci, R. and Martin, L. (2010) Awareness of Risk Factors among Persons at Risk for Lung Cancer, Chronic Obstructive Pulmonary Disease and Sleep Apnea: A Canadian Population-Based Study. Canadian Respiratory Journal, 17, 287-294. https://doi.org/10.1155/2010/426563

[9] Li, Q., Dresler, C., Heck, J.E., Allwright, S., Haglund, M., Sanchez, S., Kralikova, E., Strucker, I., Tamang, E., Gritz, E.R. and Hashibe, M. (2010) Knowledge and Beliefs about Smoking and Cancer among Women in Five European Countries. Cancer Epidemiology, Biomarkers \& Prevention, 19, 2811-2820.

https://doi.org/10.1158/1055-9965.EPI-10-0432

[10] Low, E.L., Simon, A.E., Lyons, J., Romney-Alexander, D. and Waller, J. (2012) What Do British Women Know about Cervical Cancer Symptoms and Risk Factors? European Journal of Cancer, 48, 3001-3008.

https://doi.org/10.1016/j.ejca.2012.05.004

[11] Mazières, J., Pujol, J.L., Kalampalikis, N., Bouvry, D., Quoix, E., Filleron, T., Targowla, N., Jodelet, D., Milia, J. and Milleron, B. (2015) Perception of Lung Cancer among the General Population and Comparison with Other Cancers. Journal of Thoracic Oncology, 10, 420-425. https://doi.org/10.1097/JTO.0000000000000433

[12] Siahpush, M., McNeill, A., Hammond, D. and Fong, G.T. (2006) Socioeconomic and Country Variations in Knowledge of Health Risks of Tobacco Smoking and Toxic Constituents of Smoke: Results from the 2002 International Tobacco Control (ITC) Four Country Survey. Tobacco Control, 15, iii65-iii70.

[13] Chen, X., Gorlov, I.P., Ying, J., Merriman, K.W., Kimmel, M., Lu, C., Reyes-Gibby, C.C. and Gorlova, O.Y. (2012) Initial Medical Attention on Patients with EarlyStage Non-Small Cell Lung Cancer. PLoS ONE, 7, e32644. https://doi.org/10.1371/journal.pone.0032644

[14] (2012) Attitudes of Europeans towards Tobacco. Special Eurobarometer 385. http://www.ec.europa.eu/health/tobacco/docs/eurobaro attitudes towards tobacco 2012 en.pdf 


\section{Appendix}

\section{Questionnaire}

1) Lung cancer is connected to many risk factors. Cite any risk factors that you know.

2) Below are some risk factors connected to various diseases. Which ones are connected to lung cancer in your opinion? Choose all correct answers.

-Smoking

-Passive smoking

-Air pollution

-Other pulmonary diseases, for example chronic obstructive pulmonary disease

-Previous lung cancer or family history of lung cancer

-Contact with chemicals, for example radon

-Contact with asbestos

-Radiation

3) Does smoking increase the chance of getting lung cancer? Choose one answer.

-Yes, significantly

-Yes, but not significantly

-Maybe

-Other factors are more important

-No, definitely not

-Don't know

4) Lung cancer can cause various symptoms. Cite the lung cancer symptoms you are aware of.

5) Below are different symptoms. Which of these could be linked with lung cancer? Choose all correct answers.

-Prolonged cough

-Coughing blood

-Shortness of breath

-Chest pain

-Prolonged respiratory infection

-Wheezing

-Hoarseness

-Weakness

-Weight loss

-Loss of appetite

6) Which one of the following claims is correct? Choose one answer.

-Lung cancer only affects men

-Lung cancer affects men more often than women

-Lung cancer affects men and women equally

-Lung cancer affects women more often than men

7) Do you think lung cancer is curable? Choose one answer.

-No, never 
-Yes, when detected early

-Yes, in the modern times almost always

-Yes, always

Finally could you please answer these general questions about yourself:

What is your:

Age: years

Level of education:

-primary

-secondary

-vocational

-higher

Do you smoke?

-Yes $\rightarrow$ for how long? years

-No

-never smoked

-quit smoking more than 1 year ago

Gender:

-Male

-Female

Submit or recommend next manuscript to SCIRP and we will provide best service for you:

Accepting pre-submission inquiries through Email, Facebook, LinkedIn, Twitter, etc. A wide selection of journals (inclusive of 9 subjects, more than 200 journals) Providing 24-hour high-quality service User-friendly online submission system Fair and swift peer-review system Efficient typesetting and proofreading procedure Display of the result of downloads and visits, as well as the number of cited articles Maximum dissemination of your research work

Submit your manuscript at: http://papersubmission.scirp.org/ Or contact ojrd@scirp.org 